Document downloaded from:

http://hdl.handle.net/10251/47381

This paper must be cited as:

Alcázar Ortega, M.; Álvarez Bel, CM.; Escrivá Escrivá, G.; Domijan, A. (2012). Evaluation and assessment of demand response potential applied to the meat industry. Applied Energy. 92:84-91. doi:10.1016/j.apenergy.2011.10.040.

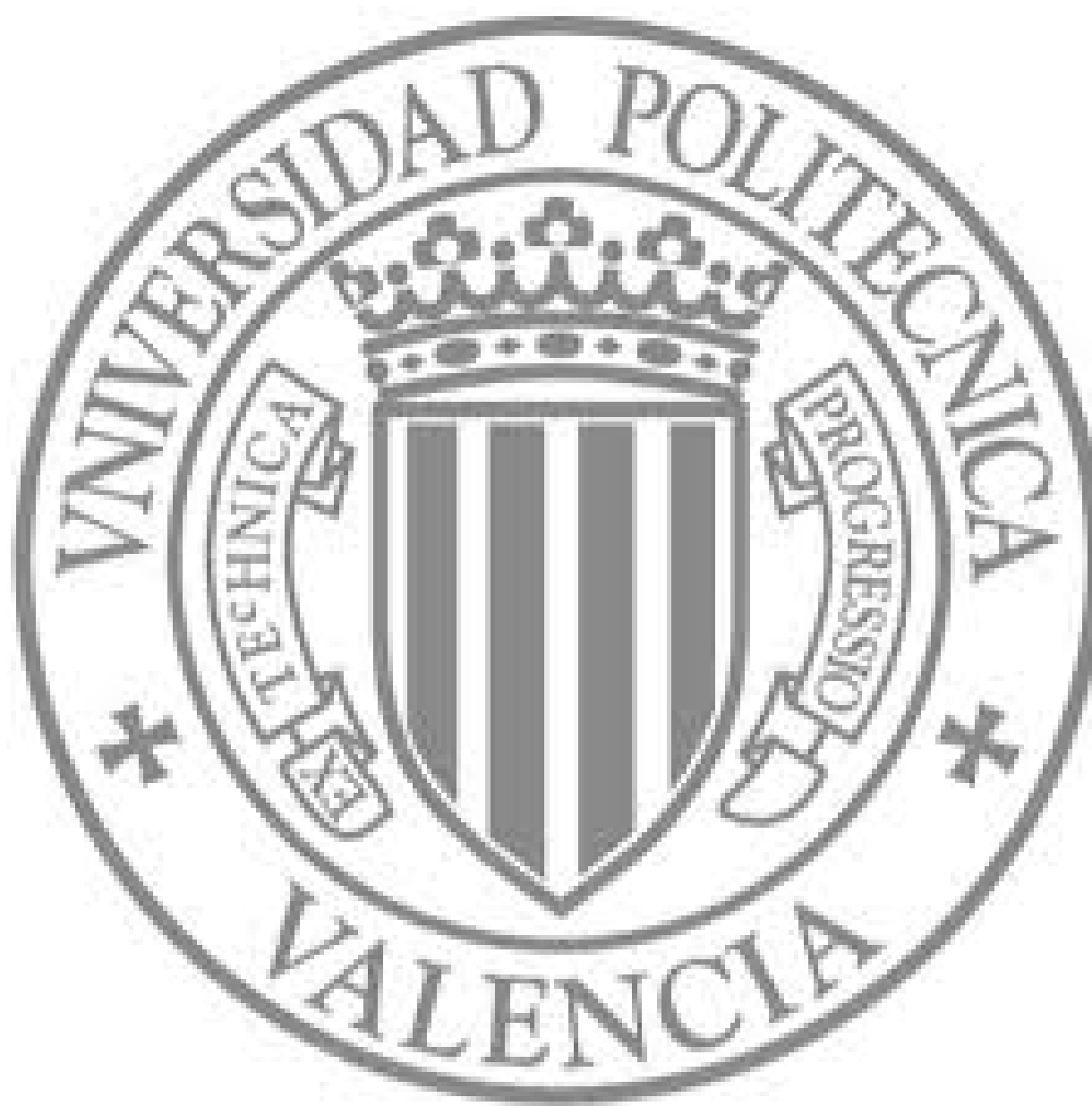

The final publication is available at

http://dx.doi.org/10.1016/j.apenergy.2011.10.040

Copyright Elsevier 


\title{
EVALUATION AND ASSESSMENT OF DEMAND RESPONSE POTENTIAL APPLIED TO THE MEAT INDUSTRY
}

\author{
Manuel Alcázar-Ortega $\left({ }^{*}\right)\left({ }^{a}\right)$, Carlos Álvarez-Bel $\left({ }^{a}\right)$, Guillermo Escrivá-Escrivá( ${ }^{(a)}$, Alexander \\ $\operatorname{Domijan}\left({ }^{b}\right)$
}

( $\left.{ }^{a}\right)$ Universidad Politécnica de Valencia, Institute for Energy Engineering

Camino de Vera, s/n, edificio 8E, escalera F, 5ª planta. 46022 Valencia (SPAIN)

(e-mail: malcazar@iie.upv.es)

$\left(^{b}\right)$ University at Buffalo, Power Center for Utility Explorations

332 Bonner Hall, Buffalo, NY 14260-2050, USA

(e-mail: adomijan@buffalo.edu)

\section{Abstract}

Demand Response has proven to be a useful mechanism that produces important benefits for both the customer and the power system. In the context of an increasingly competitive electricity market, where prices are constantly rising and the presence of renewable energy resources is gaining prominence, this paper analyzes the flexibility potential of customers in the meat industry, based on the management of the most energy consuming process in this type of segment: cooling production and distribution.

The effectiveness of the proposed actions has been successfully tested and validated in an active factory that produces cured ham in Spain, where savings of about $5 \%$ in the total annual cost of electricity have been assessed, together with power reductions in the range of $50 \%$ of the total

\footnotetext{
* Corresponding Author: Manuel Alcázar-Ortega. Institute for Energy Engineering. Universidad Politécnica de Valencia. Camino de Vera, s/n, edificio 8E, escalera F, 5ª planta. 46022 Valencia (SPAIN). Telf. +34 963877271 Fax: +34 963877 272 email: malcazar@iie.upv.es
} 
peak demand of the studied facilities. Such results demonstrate the efficacy of these techniques, and they open the door to an innovative perspective on the evaluation of flexibility among customers which are traditionally considered rigid, providing a novel approach to the management of customer infrastructures in order to exploit their flexibility in electricity markets.

\section{Keywords: Food Industry, Load Management, Power Control, Power Demand, Production} Management

\section{Introduction}

The meat and poultry industry is one of the most representative sectors among different industrial activities in diverse countries. It is the largest segment in U.S. agriculture [1], where the poultry and pork segment represents $16 \%$ of total production worldwide [2] (see Table 1). The share for the European Union is similar, at $18 \%$ of total global production. In the case of Spain, the production of different pork goods, such as cured ham or deli products, is well-recognized around the world. Spain produces $3 \%$ of total pork worldwide.

Energy use is considerable for this type of consumer, and the meat industry has been identified as one of the most suitable segments for demand response implementation [3, 4]. Heat, ventilation and cooling production loads are among the most energy consuming processes in the meat processing industry [5]. Electricity consumption is mainly used for cooling and ventilation, while fossil fuels such as natural gas or diesel are generally used for heating processes. In the meat industry, cooling production and distribution constitutes between $45 \%$ and $55 \%$ of the total final electricity consumption on working days [6], making this the most energy-intensive process for most consumers in this segment.

Different works have been presented in the past $[7,8]$ in order to evaluate customer demand response in different sectors (mainly for commercial and industrial segments). In those cases, flexibility has traditionally been related to the ability of a system to adapt itself to changes $[9,10]$ or how well a manufacturing system can absorb these changes in any of the system entities or the external environment [11]. However, no examples of previous research were found that described 
how to determine potential customer flexibility in order to take advantage of different prices of electricity throughout time. This is especially true when such actions are applied to sensitive processes directly related to the quality of the final product, which tend to make customers wary of changing any element or parameter of those processes.

A wide range of benefits could be obtained by customers if they decide to use the flexibility they have. However, final customers are not yet acquainted with demand response capabilities, in large part due to lack of information and training on the benefits that they can bring [12].

According to those facts, this paper presents a novel approach where flexibility is understood not as the capacity of a system to adapt itself to changes, but as the ability of customers to modify the power demand from their expected consumption either as a response to a requirement from the grid operator or other demand response provider when a reliability problem occurs in the system or as a reaction to variation in the price of electricity. While demand response actions can take place at any time, not only during the peak period [13], their implementation could be key during peak and non-peak periods of electricity use, and are usually less costly than building more power plants [14].

The proposed flexibility strategy in this paper is based on the interruption of the electricity supply used in cooling production so that the thermal inertia of the system can be used to keep both temperature and humidity within acceptable limits. This work has been validated by means of real tests in industrial facilities, where the proposed flexibility strategy has been implemented in consumers. The studied segment (coded by the Classification of Economic Activities in the European Community, NACE rev. 2 10.1, [15]) includes processing and preserving of meat as beef, pork, lamb, rabbit, mutton, camel, etc. (NACE 10.11), processing and preserving of poultry meat (NACE 10.12) and production of meat and poultry meat products (NACE 10.13).

The paper is organized as follows. Section 2 presents a methodology to evaluate the customers' technical potential to manage their energy consumption. Once a technical evaluation has been performed, the economic and environmental assessments for proposed strategies are discussed in section 3. The validation of these techniques in a real customer is considered in detail in section 4 and, finally, some conclusions are shown in section 5 . 


\section{Technical Evaluation of flexibility}

As stated in the introduction, cooling production and distribution is the main electrical consumption in this type of facilities. Consequently, the flexibility potential for this process will be evaluated, since small actions on such process could imply significant savings for the factory as a whole.

\subsection{Use of cooling in the meat industry}

Many different configurations can be found with regard to the use of cooling in the meat industry, depending on the configuration of the production and processes as well as the type of goods produced in each particular factory. However, after studying in detail the use of cooling in different factories located in Spain, where a wide range of different meat products are manufactured, four basic types of circuits for cooling production (cooling lines) can be established for a typical meat production plant, as shown in Figure 1:

- Freezing line: This is used in freezing chambers to preserve the meat at a very low temperature. The primary temperatures for this type of circuit are usually between -35 and $-40^{\circ} \mathrm{C}$. Another different and dedicated circuit at a lower temperature may be available if a deep-freezing tunnel is used for freezing rather than preserving the meat; this is a common practice in slaughterhouses.

- Preserving line: When the aim of a chamber is to keep fresh meat rather than frozen meat, primary temperatures between -10 and $-15^{\circ} \mathrm{C}$ usually satisfy that requirement.

- Air conditioning line: Used for maintaining the required cooling conditions in working rooms. Values of primary temperature for this line vary from $0^{\circ}$ to $-5^{\circ} \mathrm{C}$ to keep the temperature of the room within a range varying from $5^{\circ}$ to $10 \stackrel{\circ}{ } \mathrm{C}$, depending on the use of the room.

- Drying lines: In factories which produce cured meat products such as ham or deli meats, there are usually two specific lines for drying processes; these account for most of the electricity consumption in the plant. One of these lines, the Low Temperature Line, is set between -10 and $-5^{\circ} \mathrm{C}$, and can also be used as a preserving line. The 
second drying line, called the High Temperature Line, is adjusted between 0 and $-5^{\circ} \mathrm{C}$. Sometimes it is used for air conditioning purposes, although this option is less frequent. Both the high and low temperature lines, combined with other hot water lines, keep the temperature of drying rooms under control and reduce the level of humidity to levels mandated by the professionals in charge of the drying stage.

Table 2 shows the breakdown of electricity consumption for three different factories which produce cured meat products in three places with different climates: northern (Continental Mediterranean with cold winter climate), western (Continental Mediterranean with hot summer climate) and central Spain (Warm Mediterranean climate). For this type of factory, drying processes usually consume the largest amount of energy, reaching values of $65-81 \%$ of total electricity consumption. The reason is that the cooling in drying rooms is aimed not at refrigeration, but reduction of the humidity in meat, achieved by lowering the temperature of moist air in contact with the meat to the dew point.

\subsection{Flexibility strategies}

Several actions can help customers to take advantage of their flexibility potential. These actions have been identified in a study performed by the authors over a dozen of different factories, from slaughterhouses to plants which produce cooked, cured and other deli products. Moreover, some of them have been tested, as shown in section 4 .

The identified actions could be divided into the following types:

- Type 1: Actions that require no additional investment and have no impact on the customer activity. These actions are related to the interruption of inefficient devices responding to high market prices whose operation does not render a profitable service. An example could be nighttime air conditioning in offices or HVAC devices functioning in temporarily idle workspaces. No investment is required for the implementation of these actions, since existing human resources can connect and disconnect the devices.

- Type 2: Actions that require investment and have no impact on factory production. 
These actions can be further divided into two groups: Sub-group 1 includes an improved or automated version of the actions considered in Type 1 above, where investment in an automatic control and management system will enhance effectiveness and reliability ${ }^{1}$. Sub-group 2 consists of a set of more sophisticated actions, such as ice storage [17], industrial use of free-cooling, etc. While the first set of actions aims to reduce unnecessary energy consumption and service use, actions included in subgroup 2 endeavor to reduce the total cost (economic and environmental) associated with the required energy use, either by directly reducing it or by displacing its production to cheaper energy cost periods (nighttime).

- Type 3: Actions with an admissible impact on production that may or may not require additional investment. The use of this type of actions is the most innovative aspect of the research presented in this paper because they have not been traditionally considered due to concerns about the possible impact on the final product. A typical example of application is the disconnection of loads related to cooling production and distribution in the factory. It is essential to guarantee that critical process parameters such as temperature or humidity will not reach unacceptable values that could compromise product quality.

\subsection{Technical assessment of flexibility in drying rooms}

Maintaining controlled temperatures and humidity inside drying rooms is elemental to the process of drying in food production factories, so any action that implies a degradation of these parameters will be unacceptable. Taking this fact into account, flexibility actions carried out must guarantee that variations in those parameters are maintained within acceptable limits.

\footnotetext{
${ }^{1}$ Authors presented in [16] a new Integral Management System (IMS), based on a secure website. This novel IMS is able to achieve decrements of $20 \%$ by means of active control and includes a set of new tools and techniques in order to improve the management of different energy resources used in existing infrastructures, resulting in a reduction in energy consumption, an increment in overall efficiency and the control of distributed loads.
} 
Figure 2 schematically represents how the drying process works in a meat drying room. In step

161 1, dry air comes into contact with the surface of the meat inside the drying room (point 1 to point 2),

162 absorbing the humidity present on the surface of the meat. This results in the humidity ratio $\omega$

163 growing adiabatically from $\omega_{1}$ to $\omega_{2}$ [18], as shown in Figure 3 . When moist air enters the air drying

164 unit, temperature is reduced (point 2 to point 3 ) until reaching dew point. Moisture condensation

165 occurs when moist air is cooled to a temperature below its initial dew point [19]. From point 3 to

166 point 4 , the temperature decreases while the air drives the water out; since the humidity ratio is

167 lower, the capacity of the air to hold the evaporated water is reduced. Dry air is heated again (point 4

168 to point 1) in order to maintain the temperature inside the drying room, leaving the air drying unit in

169 the conditions found at point 1

170 Customers' technical potential to manage their energy consumption is evaluated by classifying

171 the demand by different end-uses or processes. Figure 4 illustrates a theoretical flat load curve for a

172 process "i" (i.e. cooling in a typical food factory). For each of the processes "i", it is necessary to

173 assess the following variables:

- Energy reduced during the action $\left(\mathrm{E}_{1, \mathrm{i}}\right)$

- Additional energy consumed before the flexibility action $\left(E_{2, i}\right)$ in order to adapt the process for the reduction or interruption

- Additional energy consumed after the action $\left(E_{3, i}\right)$, in order to re-establish the initial conditions

From $t_{0, i}$ to $t_{1, i}$ an amount of energy $\left(E_{2,1}\right)$ is consumed in order to make adaptations to prepare for an interruption. Between $t_{1, i}$ and $t_{2, i}$, the interruption occurs, so the energy package $E_{1, i}$ is not consumed. At $t_{1,1}$, the interrupted supply is switched back on, and an extra consumption $E_{3, i}$ is produced to re-establish the original temperature setting. $\ln t_{3, \mathrm{i}}$ the load curve returns to the initial level of demand.

The net energy $E_{s, i}$ saved during the flexibility action applied to the process "i" (cooling in this case) can be calculated as follows:

$$
\left.E_{s, i}=E_{1, i}-E_{2, i}+E_{3, i} \bar{\gamma} \int_{t=t_{0}}^{t=t_{3}} \mathbf{P}_{0, i}(t)-P_{f, i}(t)\right] d t
$$


$E_{s, i}$ is evaluated in (1) as the difference between the energy saved during the flexibility action

$188\left(\mathrm{E}_{1, \mathrm{i}}\right)$ and the additional energy consumed during the preparation $\left(\mathrm{E}_{2, \mathrm{i}}\right)$ and recovery $\left(\mathrm{E}_{3, \mathrm{i}}\right)$ periods.

$189 \mathrm{P}_{0, \mathrm{i}}(\mathrm{t})$ is the load curve of the process "i" when any flexibility action is not performed; and $\mathrm{P}_{\mathrm{f}, \mathrm{i}}(\mathrm{t})$ is the 190 load curve of the process after applying the flexibility action. The flexibility action is delineated

191 between $t_{1, i}$ and $t_{2,1}$, while the preparation period takes place from $t_{0, i} t_{1, i}$ and the recovery period is 192 defined between $t_{2, i}$ and $t_{3,1}$.

193 There are different ways to assess the load shape that would be demanded without flexibility 194 actions. When the power load curve of a process has a flat shape (this is the case of cooling in a meat products factory), as shown in Figure 4, the straightforward method proposed and validated by the authors in [20] can be applied. This method is based on the evaluation of the average power demanded when no flexibility actions are applied, and the subsequent extrapolation to time periods when the load shape is modified due to reductions and recovery periods.

\section{Economic and environmental application}

The economic evaluation of flexibility requires a cost-benefit analysis in order to assess the net benefit that would provide the customer with enough incentive to reduce its load. The customer must evaluate the amount of money, $\mathrm{S}_{\mathrm{s}}$, saved during the flexibility action due to the energy not consumed or shifted to cheaper periods, as well as additional expenses, $\mathrm{C}_{\mathrm{f}}$, incurred when flexibility actions are performed. After that, it should establish the value of the benefit, $B_{N E}$, it expects in exchange for offering the service to the system. These parameters are analyzed below. the amount of money $\left(\mathrm{S}_{\mathrm{s}}\right)$ saved during the flexibility action can be calculated by using the formula:

$$
S_{s}=S_{1}-\boldsymbol{Q}_{2}+S_{3} \bar{\gamma} \sum_{k=1}^{3} E_{1}^{k} \cdot p_{k}-\left[\sum_{k i=1}^{3} E_{2}^{k} \cdot p_{k}+\sum_{k=1}^{3} E_{3}^{k} \cdot p_{k}\right]
$$

where $S_{1}$ is the amount of money saved during the interruption, and $S_{2}$ and $S_{3}$ correspond to

213 the extra costs generated by the consumption before and after the interruption (preparation and 
recovery periods). $E_{1 k}$ is the amount of avoided energy for each " $k$ " period of time during the interruption (on-peak, shoulder and valley). Similarly, $E_{2 k}$ and $E_{3 k}$ are the amounts of additional energy consumed during the preparation and recovery time. It is important to point out that using flexibility may afford economic savings to customers even if no energy savings are achieved. These benefits can easily be calculated by using this equation.

\subsection{Cost of flexibility $\left(C_{f}\right)$}

The use of flexibility may entail additional direct and/or indirect costs for customers that need to be evaluated. Direct costs relate to the technical capacity for carrying out a flexibility action, while indirect costs refer to those incurred as a consequence of the implementation of flexibility actions (requirement of additional manpower, loss of productivity, etc).

\subsection{Payments from the System $\left(P_{M}\right)$ and Expected Benefit $\left(B_{N E}\right)$}

Customers pay the power system in exchange for their electricity supply. Conversely, the power system receives a service when customers participate in demand response programs and must compensate them for its value.

The payment method for providing a demand response service is established in the framework of an organized demand response program, and the amount paid to the customer $\left(\mathrm{P}_{\mathrm{M}}\right)$ will be essential to determining whether the customer participates.

Customers must specify the value they require to modify their loads $\left(B_{N E}\right)$, which depends on their own market strategy. As a result of their compliance, they will reduce their loads when the net amount of money they receive $\left(B_{R}\right)$ is equal to or higher than the benefit they expect to receive, as illustrated by the equation:

$$
B_{N E} \leq B_{R}=S_{S}+P_{M}-C_{f}
$$

Consequently, the customer will only modify its load curve when the payment $\left(P_{M}\right)$ that the customer receives from the demand response program operator for providing a service to the system satisfies the following condition:

$$
P_{M} \geq B_{N E}-\boldsymbol{\$}_{S}-C_{f}
$$



$\left(B_{N E}\right)$ is the margin of decision $\left(M_{D}\right)$, which could be calculated as an index to verify the customer's potential participation in the DR program:

- If $M_{D}<0$, the customer will not participate in the demand response program, as no benefits are obtained.

- If $M_{D} \geq 0$, the customer will provide the demand response service, modifying the

\section{Application to a cured ham factory}

The effectiveness of actions designed and justified in the previous section, including the impact that flexibility may have on the quality of the product, has been validated in an industrial cured ham factory in Spain. Customers may reduce their energy consumption during certain periods of time and thereby obtain an appreciable profit. Consequently, this assessment has been performed by means of a set of experiments based on the interruption of certain loads during peak periods. 
The studied factory is located at an altitude of $529 \mathrm{~m}$ above sea level, which means an atmospheric pressure of $94.8 \mathrm{kPa}$.

The experiment was divided into two phases. The first phase consisted of a pre-evaluation of flexibility applied to the part of the cooling system (chillers and pumps) that supplies service to the drying rooms. The installed power of these devices is $676.5 \mathrm{~kW}$, and their consumption represents $37 \%$ of total electricity consumption in the factory. During this phase, daily interruptions of one hour were performed for one week. Once the effectiveness of this action was validated, a second and more intensive campaign of interruptions was carried out, and daily interruptions of four hours, two in the morning and two in the afternoon, were applied.

\subsection{Pre-evaluation}

The season selected for the pre-evaluation stage was the third week of January, 2010, as January and February have the highest on-peak prices for electricity according to the customer supply contract. Tests consisted of one-hour interruptions per day (12:00-1:00 pm), as shown in Figure 6, where the load curve of one day where flexibility was applied is compared to the profile for the previous day, when no interruption was performed

The evolution of humidity and temperature was registered in order to ensure that these parameters were maintained within acceptable limits. Table 4 and Table 5 show this evolution, registered separately in four different drying rooms.

These tables show that variations obtained during the test for the different rooms were lower than $8 \%$, within the range of usual deviations in these parameters and therefore acceptable to the factory's quality technicians. The measurement taken at 13:30 shows that the set point values are restored just half an hour after the interruption ends.

By applying the methodology detailed in section 2 and 3 , we can estimate that power reductions during on-peak periods are about $22.9 \%$ of the total demand of the factory. This means that savings of $338 \mathrm{kWh}$ can be achieved for one hour (including the additional consumption during the recovery period, which is estimated at $58 \mathrm{kWh}$ ), or a reduction of $3.6 \%$ in the consumption of the process and $1.2 \%$ in the total electricity consumption of the factory on a working day. If this reduction is extrapolated to the whole factory, a total potential of $52.6 \%$ is possible, given that cooling is 
responsible for $85 \%$ of total consumption, and the considered cooling system represents $37 \%$ of total electricity consumption.

\subsection{Campaign of interruptions}

After proving the effectiveness of proposed actions, a more intensive campaign of interruptions was performed. During February 2010, two daily interruptions of two hours each were performed on working days. Figure 7 shows different daily load profiles when interruptions were performed, as well as an average profile and the standard deviation, represented below.

Interruptions were carried out during on-peak periods, which are established in the contract from 10:00 am to $1: 00 \mathrm{pm}$ and from 6:00 pm to 9:00 pm in December, January and February. Because daily interruptions of six hours were considered unacceptable by the customer, only the last two hours of each peak period were used for flexibility purposes. Consequently, the reconnection of cooling devices took place during shoulder periods when prices were lower. As illustrated in Figure 7, the energy saved during each interruption is much higher than that consumed during the recovery period. The load curve of the different processes was measured by means of a set of meters installed in different lines of the factory and connected to a central energy and management system, designed and presented by the authors in [21]. The average evolution of humidity and temperature registered during the first daily interruptions is shown in Table 6 and Table 7. As concluded in the pre-evaluation tests, variations remain within acceptable limits and therefore acceptable to the factory's quality technicians

The application of these actions allowed the customer to reduce about $23 \%$ of the power peak required by the factory during the reduction, saving about $1,555 \mathrm{kWh}$ every working day in February. If these results are extrapolated to the whole cooling system, a reduction of $52.8 \%$ of the total power peak in the factory can be achieved. Taking into account that the hot weather prevents the factory to maintain interruptions for longer than 2 daily hours in summer, according to the opinion of the factory's quality technicians, results obtained for winter were extrapolated for a whole year taking into account the effect of seasonality and how such factors as external temperature and humidity affect the electricity consumption. Moreover, a new set of interruptions performed in July 2011 allowed the authors to assess daily savings of $786.7 \mathrm{kWh}$ for summer, validating the hypothesis 
considered in February 2010 when only measurements for winter were available. Consequently, equivalent savings of 405,000 kWh/year are obtained. Additionally, if real prices in the contract of the customer are considered, as well as $\mathrm{CO}_{2}$ emission factors provided by the Ministry of Industry of Spain, savings of 396 ton $\mathrm{CO}_{2} /$ year and $4.9 \%$ in the total annual cost of electricity are assessed.

\section{Conclusions}

Flexibility is playing a more and more important role when a better use of energy is pursued. Customers could achieve significant benefits when using the flexibility they may have. However, final customers are not aware about the benefits that their demand response capabilities can provide to them.

This paper provides empirical evidence on the use of flexibility in a promising sector such as the meat industry. The effectiveness of proposed flexibility actions in a cured ham factory in Spain has been tested and the results of real experiments are presented.

One of the most significant conclusions is that such actions signify a notable reduction of the peak power demanded by the customer during certain periods of time, which could reach over $50 \%$ of the total power demanded by the factory without compromising the quality of the final product. This has been demonstrated by measuring the temperature and humidity inside drying rooms during the interruptions. Variations in these parameters are within the range of usual deviations registered by meters located in different points of the chamber, producing an insignificant impact on the product. Significant economic and environmental benefits may be also achieved by customers, reaching savings of about $5 \%$ in the total annual cost of electricity.

\section{Acknowledgment}

This work was supported by the Spanish Government (Ministerio Ciencia e Innovación, MICINN) under Research Project ENE2007-67771-C02-01\&02/CON.

The authors gratefully acknowledge the contributions of Campofrío Food Group, S.A. 


\section{References}

[1] The United States Meat Industry. American Meat Institute AMI. March 2009 Report. Available on http://www.meatami.com

[2] FAOSTAT. Food and Agriculture Organization of the United Nations. Annual Statistical Report, 2005. http://faostat.fao.org, accessed on February 2009.

[3] The birth of a EUropean Distributed EnErgy Energy Partnership that will help the large-scale implementation of distributed energy resources in Europe (EU-DEEP), the European Project supported by the Sixth Framework programme for Research and Technological Development. http://www.eu-deep.com

[4] Afonso, D., Pérez-Navarro, A., Encina, N., Álvarez, C., Rodríguez, J. and Alcázar, M.: "Methodology for ranking of customer segments by their suitability for distributed energy resources applications", Elsevier Energy Conversion and Management, 48, pp. 1615-1623, January 2007

[5] Alcázar-Ortega, M., Álvarez-Bel, C., Domijan, A. and Escrivá-Escrivá, G.: “Active demand response strategies to improve energy efficiency in the meat industry". World Renewable Energy Congress 2011, Linköping (Sweden), May 8-13, 2011

[6] Ramírez, C.A., Patel, M. and Blok, K. "How much energy to process one pound of meat? A comparison of energy use and specific energy consumption in the meat industry for European countries". Elsevier Energy, 31, pp. 2047-2063, September 2006

[7] Álvarez, C., Alcázar, M., Escrivá, G. and Gabaldón, A. "Technical and economical tools to assess customer demand response in the commercial sector". Elsevier Energy Conversion and Management, 50, pp. 2605-2612, July 2009

[8] Álvarez, C., Gabaldón, A. and Molina, A.: "Assessment and simulation of the responsive demand potential in end-user facilities: Application to a university customer", IEEE Trans. Power Syst., vol. 19, no. 2, pp. 1223-1231, May 2004

[9] Hakam, M.H. and Solvang, W.D. "On flexibility and sustainability in container ports". IEEE International Conference on Service Operations, Logistics and Informatics, Chicago, IL, USA July 22-24, 2009 
[10] Zelenovic, D.M. "Flexibility-a condition for effective production systems". International Journal of Production Research, Vol. 20, No. 3, pp. 319-337. May, 1982.

[11] Zahran, I.M., Elmaghraby, A.S. and Shalaby, M.A. "Evaluation of flexibility in manufacturing systems". IEEE International conference on systems, MAN, and Cybernetics, Los Angeles, CA, USA, 1990.

[12] Bourgain, $G$ (coord.) et al. Integrating distributed energy resources into today's electrical system. ExpandDER, June 2009.

[13] The Federal Energy Regulatory Commission Staff: "Draft for comment of the National Action Plan on Demand Response". March, 2010. Available online: http://www.ferc.gov

[14] Chiu, A., Ipakchi, A., Chuang, A., Qiu, B., Brooks, D., Koch, E., Zhou, J., Zientara, M.K., Precht, P.R., Burke, R. and Crowder, R.S.: "Framework for Integrated Demand Response (DR) and Distributed Energy Resources (DER) Models". NAESB \& UCAlug. September, 2009. Available online: http://osgug.ucaiug.org

[15] Statistical Classification of Economic Activities in the European Community, Rev. 2 (NACE Rev. 2). Available on http://ec.europa.eu/eurostat accessed on March 2010.

[16] Escrivá, G., Alcázar, M. and Álvarez, C. "Integral management system for the energy efficiency improvement in commercial facilities: Application to the Polytechnic University of Valencia". International Conference on Renewable Energies and Power Quality (ICREPQ'09), Valencia, Spain, April 15-17, 2009

[17] Farahani, M.E.S. and Saeidi, N. "Case study of design and implementation of a thermal energy storage system". First International Power and Energy Conference PECon. Putrajaya, Malaysia, November 28-29, 2006.

[18] Ventanas, J. "Tecnología del jamón ibérico". Ed. Mundi-Prensa, Madrid, 2001. ISBN 8471149443.

[19] ASHRAE. "Psychrometrics - SI Units Edition" in Fundamentals Handbook Ed. American Society of Heating, Refrigerating and Air-Conditioning Engineers, 2005. Chapter 6, pp. 6.16.17. 
409 [20] Alcázar-Ortega, M., Escrivá-Escrivá, G., Valencia-Salazar, I., Álvarez Bel, C. and Alfonso

410

411

412

413

414

415
Solar, D. "Validation of a methodology to assess customer demand response: application to the commercial sector". IEEE/PES - IAS Conference on Sustainable Alternative Energy. Valencia, Spain, September 28-30, 2009.

[21] Escrivá-Escrivá, G., Segura-Heras, I., Alcázar-Ortega, M.: "Application of an energy management and control system to assess the potential of different control strategies in HVAC systems". Energy and Buildings, Vol. 42, No. 11, pp. 2258-2267. November 2010. 


\section{Figure captions}

Figure 1. Scheme of processes in a typical cured meat products factory

Figure 2. Meat drying process scheme

Figure 3. Psychrometric chart for a drying room

Figure 4. Theoretical model for technical evaluation of flexibility (flat shape)

Figure 5. Economic evaluation of flexibility: cost-benefit analysis for customers

Figure 6. Pre-evaluation test performed in a cured ham factory

Figure 7. Load curves obtained during the campaign of interruptions

\section{$\underline{\text { Table captions }}$}

Table 1. Meat production around the World (2005) in miles of tones.

Table 2. Breakdown of electricity consumption in different cured meat production factories

Table 3. Emission factors for different periods in Spain

Table 4. Variation of humidity during the test in drying rooms

Table 5. Variation of temperature during the test in drying rooms

Table 6. Variation of humidity during the second campaign of interruptions in drying rooms

Table 7. Variation of temperature during the second campaign of interruptions in drying rooms 
COOLING LINE

Working Room Line

Preserving /freezing chambers

Working Room Line

Drying Line High Temperature

Working Room Line

Working Room Line

Preserving chambers
PROCESS

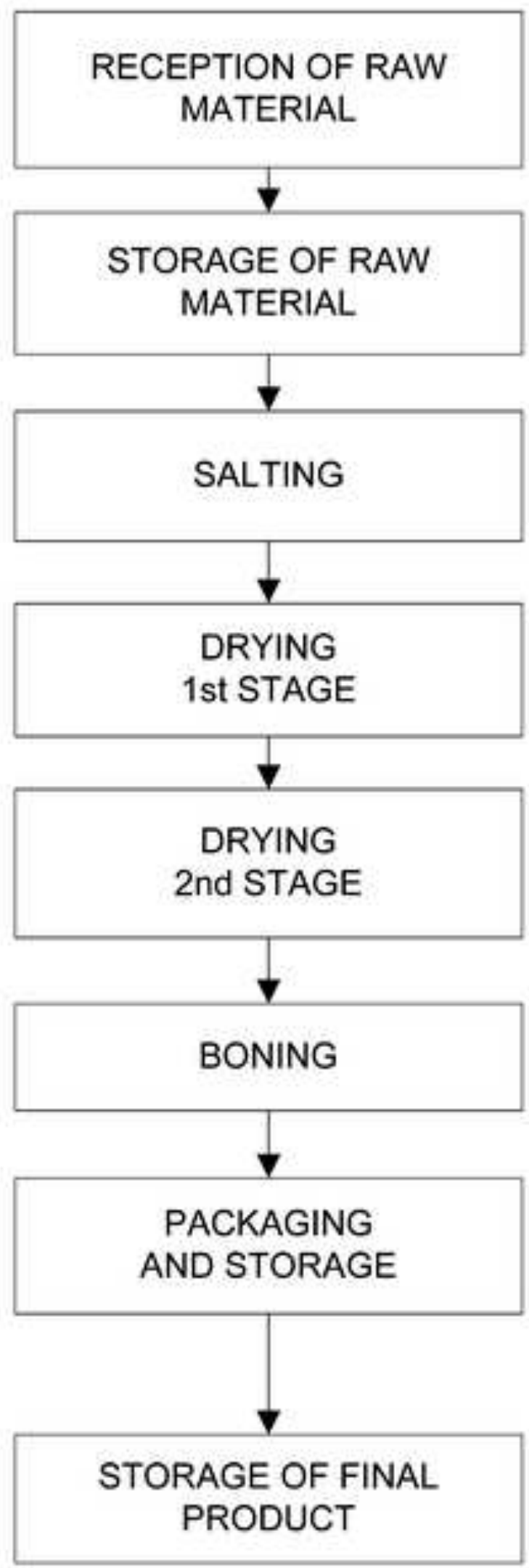




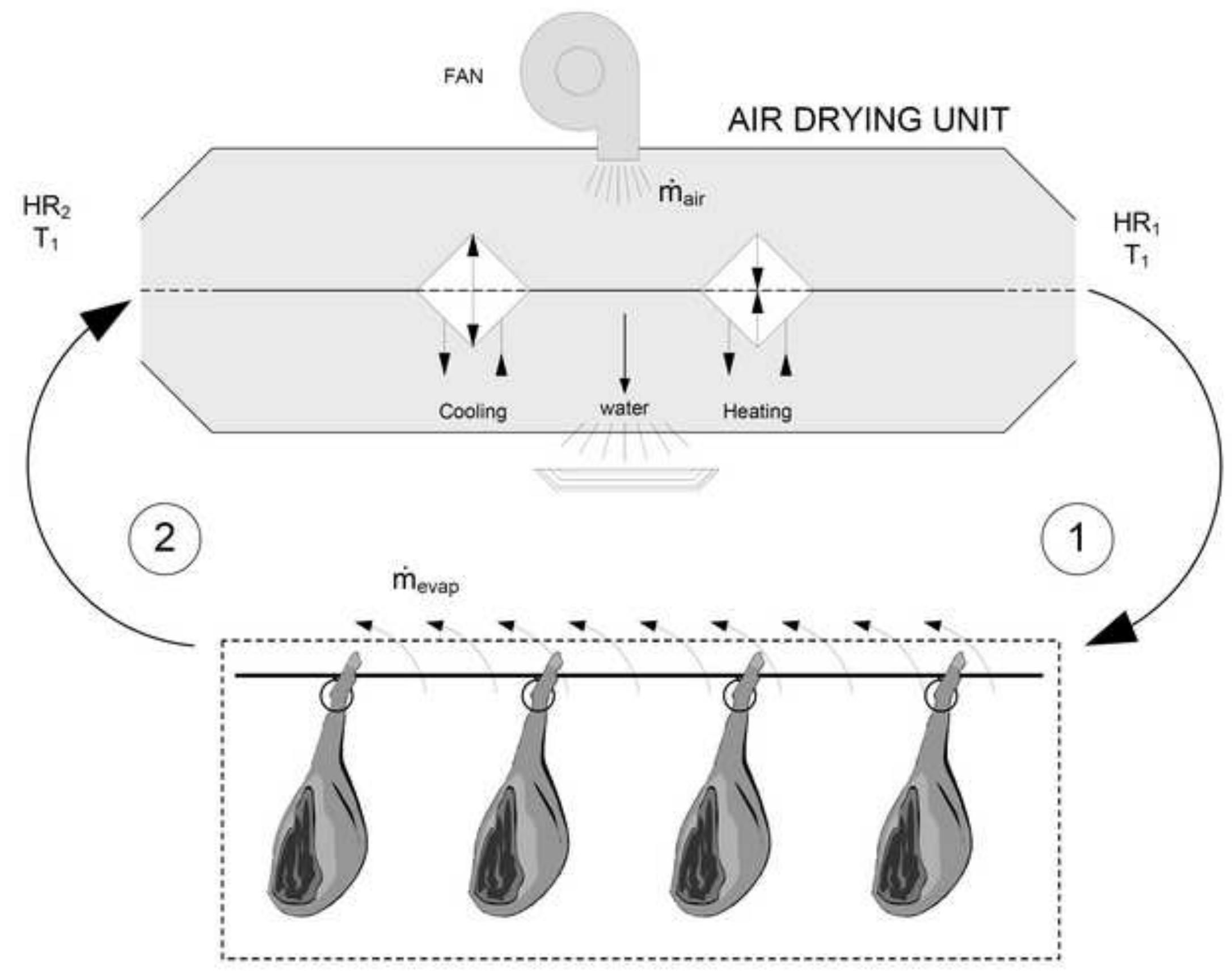




\section{Figure 3}

Click here to download high resolution image

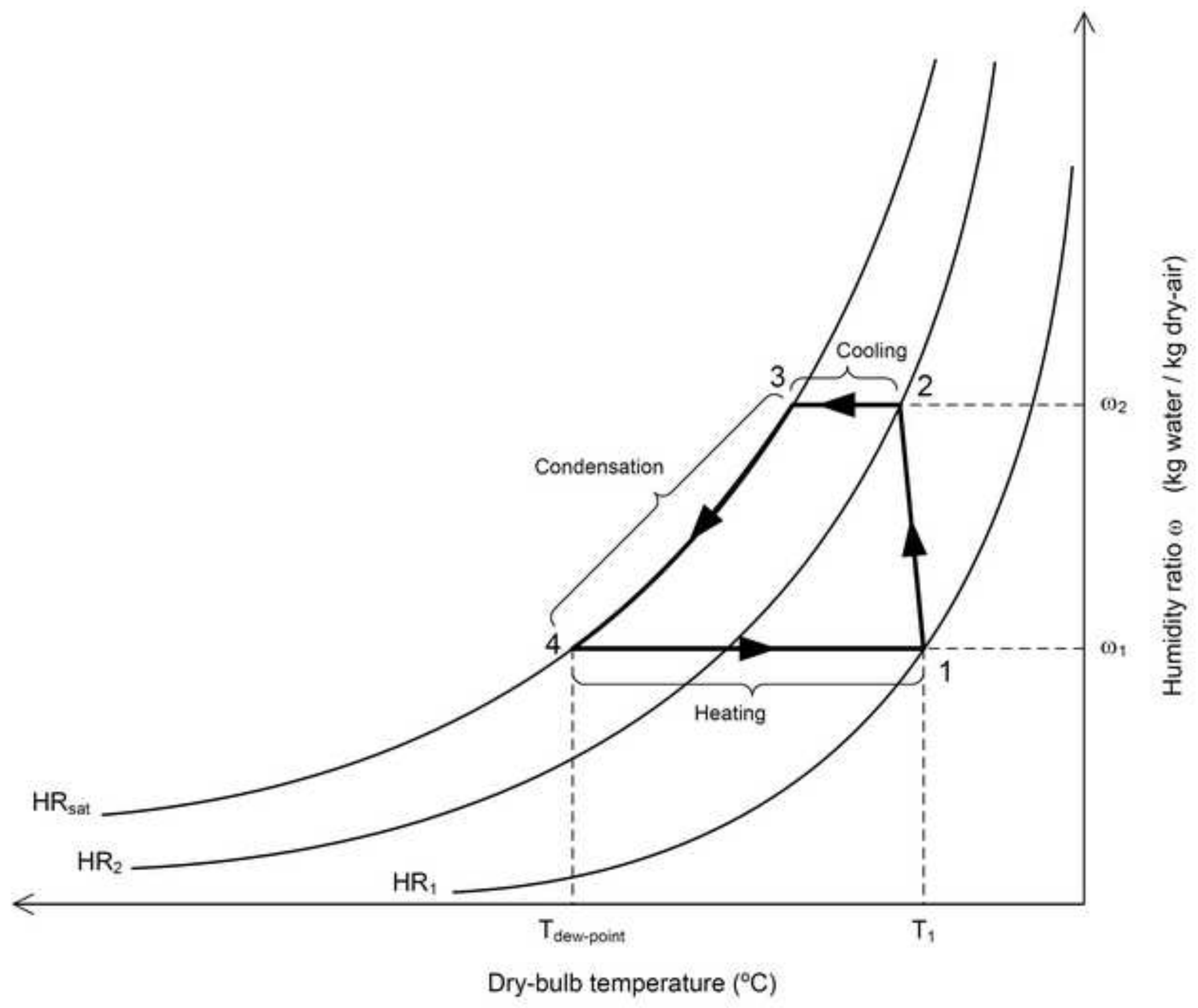




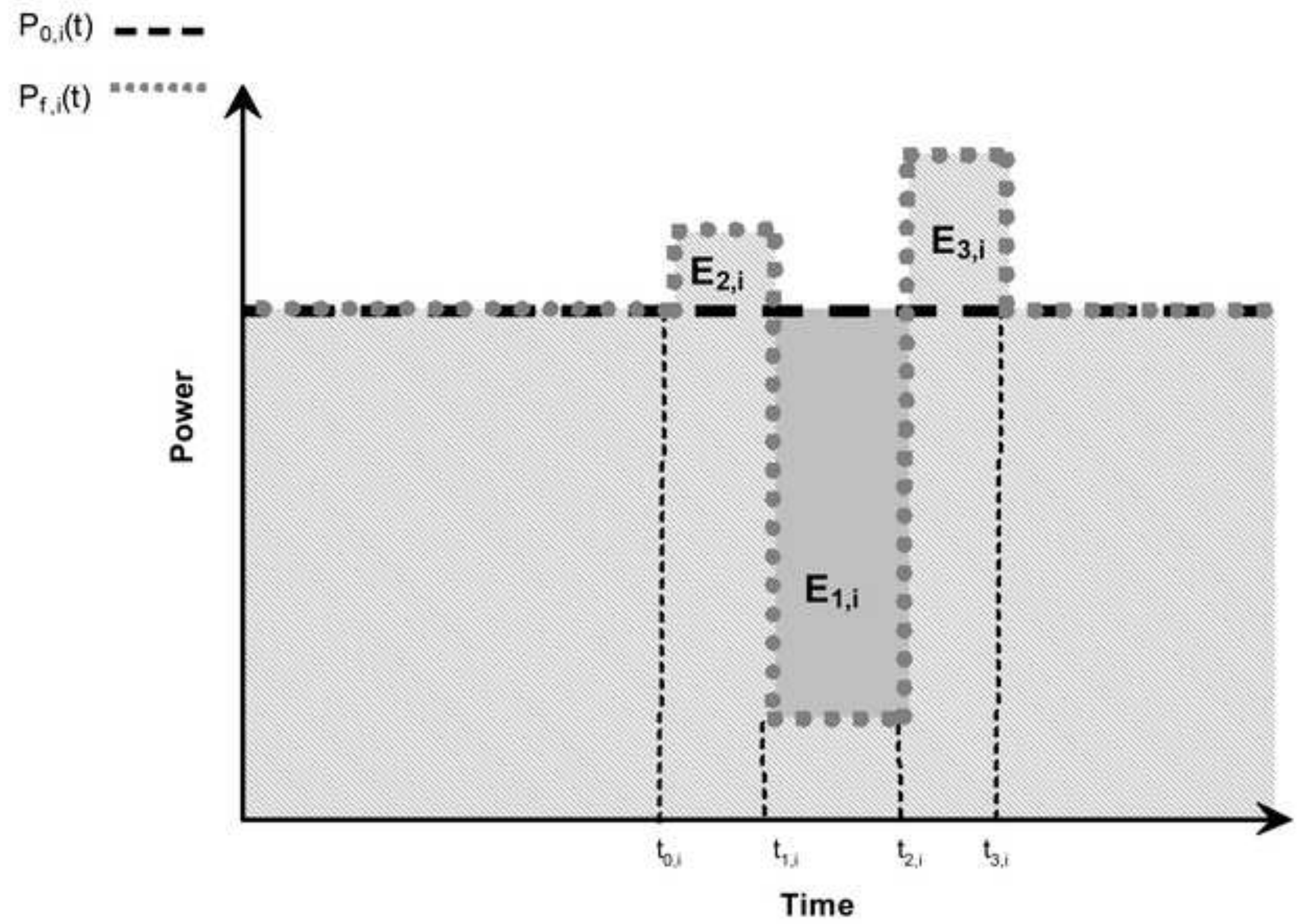




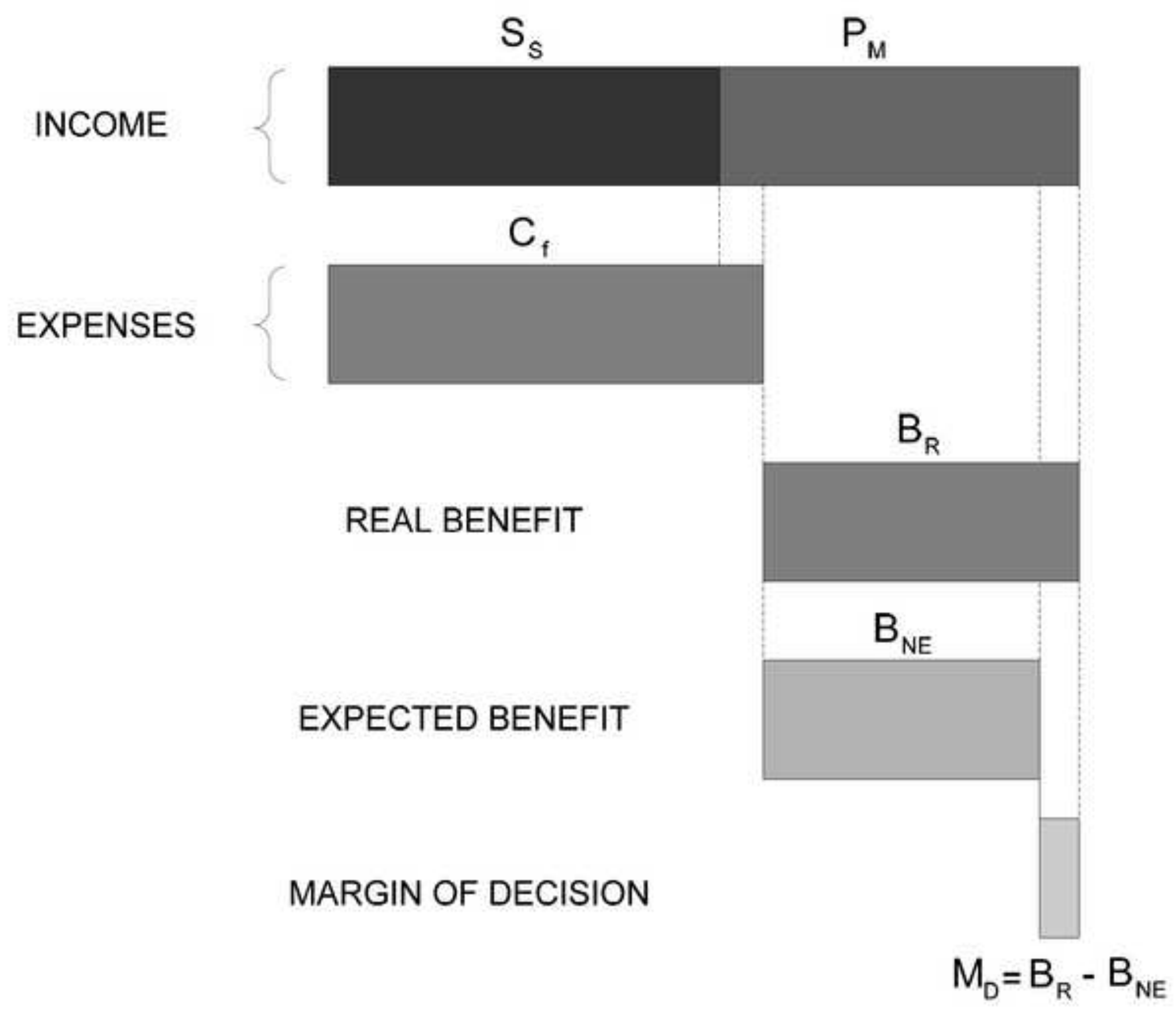




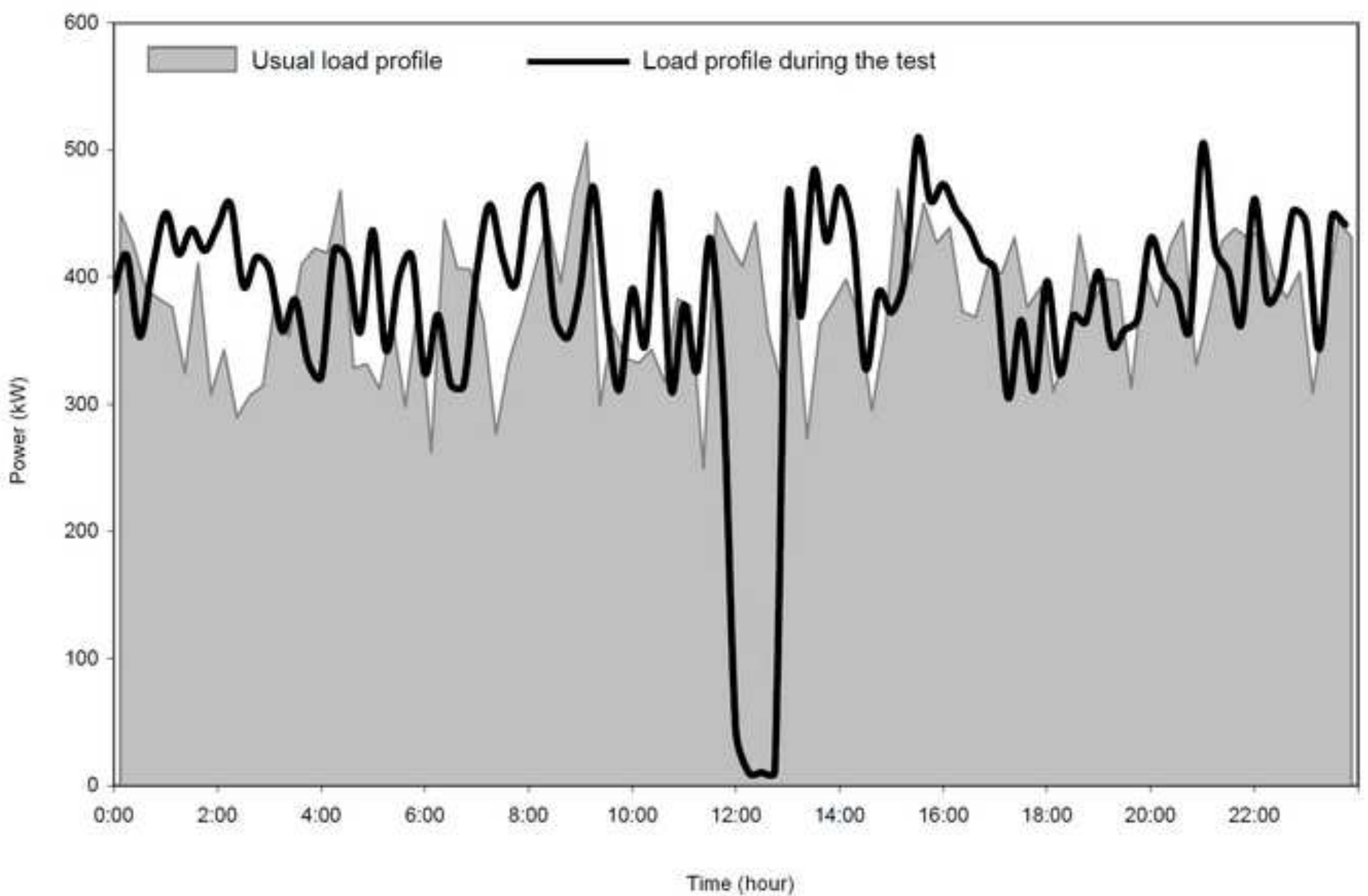




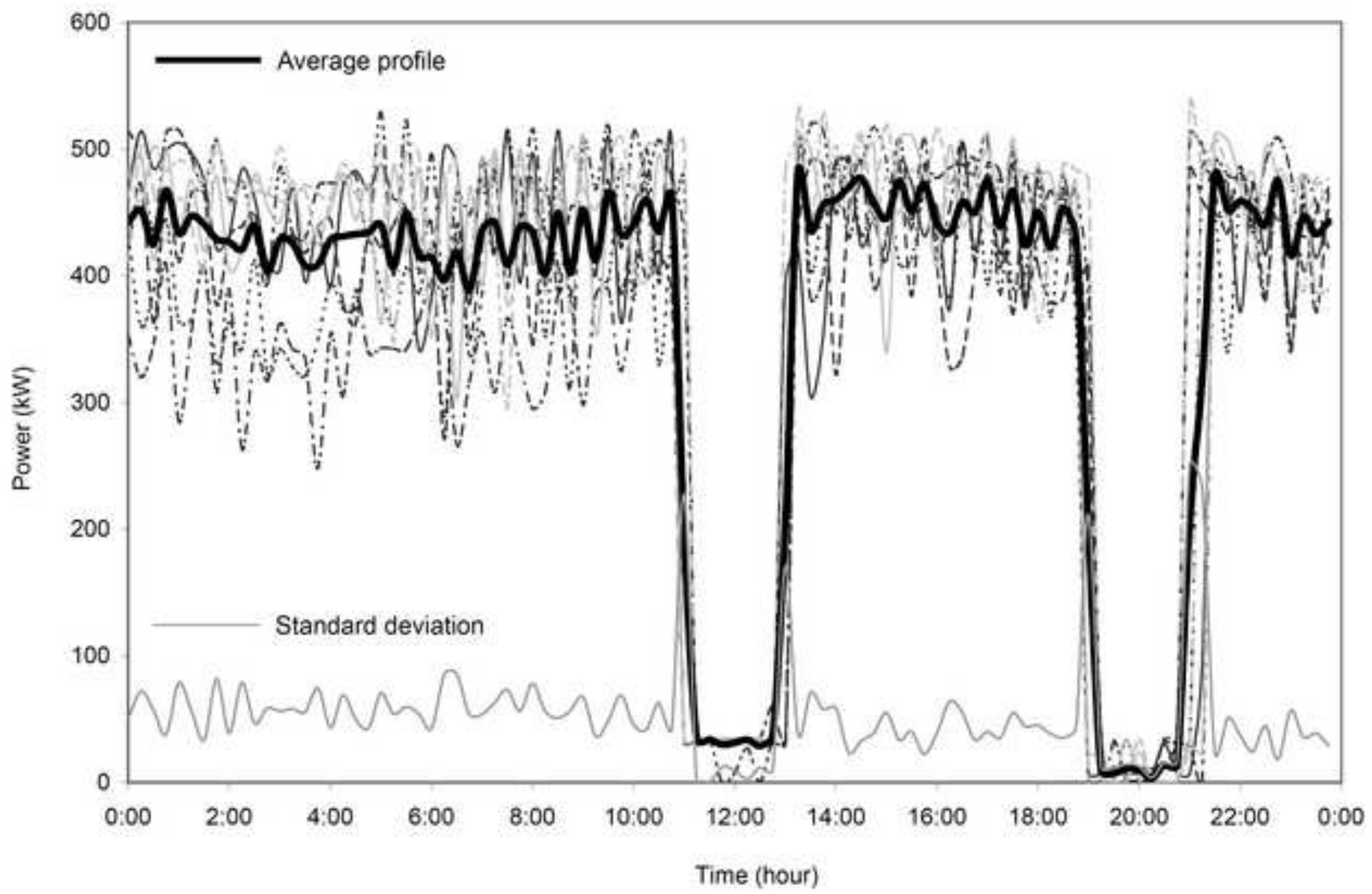


Table 1

Meat production around the World (2005) in miles of tones Source: FAOSTAT

\begin{tabular}{ccccc}
\hline Type of meat & Spain & EU & US & World \\
\hline Beef \& Buffalo & 715 & 8,066 & 11,243 & 62,748 \\
Poultry & 1,104 & 10,853 & 19,105 & 81,781 \\
Sheep \& Goat & 238 & 1,156 & 85 & 12,579 \\
Pig & 3,168 & 21,803 & 9,383 & 98,927 \\
Others & 82 & 648 & 224 & 4,512 \\
Total & $\mathbf{5 , 3 0 8}$ & $\mathbf{4 2 , 5 2 5}$ & $\mathbf{4 0 , 0 3 9}$ & $\mathbf{2 6 0 , 5 4 7}$ \\
\hline
\end{tabular}


Table 2. Breakdown of electricity consumption in different cured meat production factories

\begin{tabular}{cccc}
\hline & $\begin{array}{c}\text { Factory 1 } \\
\text { Continental } \\
\text { Mediterranean with } \\
\text { cold winter climate }\end{array}$ & $\begin{array}{c}\text { Factory 2 } \\
\text { Continental } \\
\text { Mummer climate }\end{array}$ & $\begin{array}{c}\text { Factory 3 } \\
\text { surm Mediterranean } \\
\text { climate }\end{array}$ \\
\hline Freezing Chambers & - & - & $1 \%$ \\
Preserving Chambers & $11 \%$ & $7 \%$ & $11 \%$ \\
Drying Low Temp. & $45 \%$ & $49 \%$ & $41 \%$ \\
Drying High Temp. & $41 \%$ & $36 \%$ & $42 \%$ \\
Working Rooms & $3 \%$ & $8 \%$ & $5 \%$ \\
\hline
\end{tabular}


Table 3

Table 3. Emission factors for different periods in Spain Source: Spanish Departments of Industry and Housing

\begin{tabular}{cc}
\hline Period & $\begin{array}{r}\text { Emission factor } \boldsymbol{f e}_{\mathrm{k}} \\
\left(\mathrm{tCO}_{\mathbf{2}} / \mathbf{M W h}\right)\end{array}$ \\
\hline On-peak & 0.750 \\
Shoulder & 0.649 \\
Valley & 0.517 \\
\hline
\end{tabular}


Table 4

Variation of humidity during the test in drying rooms

\begin{tabular}{cccccc}
\hline \multicolumn{2}{c}{ Humidity (\%) } & & & & \\
\hline Room & Reference & $12: 00 h$ & $12: 20 h$ & $12: 40 h$ & $13: 30 h$ \\
\hline Room A & 72.5 & 68.3 & 72.7 & 72.3 & 71.5 \\
Room B & 72.0 & 70.3 & 74.3 & 75.3 & 72.3 \\
Room C & 75.0 & 75.3 & 80.7 & 81.3 & 80.8 \\
Room D & 80.0 & 77.3 & 80.3 & 81.8 & 78.3 \\
\hline
\end{tabular}


Table 5

Variation of temperature during the test in drying rooms

\begin{tabular}{cccccc}
\hline \multicolumn{6}{c}{ Temperature $\left({ }^{\circ} \mathrm{C}\right)$} \\
\hline Room & Reference & $12: 00 h$ & $12: 20 h$ & $12: 40 h$ & $13: 30 h$ \\
\hline Room A & 30.0 & 27.0 & 28.3 & 29.3 & 27.8 \\
Room B & 18.0 & 18.3 & 18.5 & 18.3 & 18.5 \\
Room C & 8.0 & 8.0 & 8.7 & 8.7 & 8.2 \\
Room D & 4.0 & 3.7 & 3.7 & 4.2 & 4.0 \\
\hline
\end{tabular}


Table 4

Variation of humidity during the second campaign of interruptions in drying rooms

\begin{tabular}{cccccccc}
\hline \multicolumn{2}{c}{ Humidity (\%) } & \multicolumn{7}{c}{} \\
\hline Room & Reference & $11: 00 h$ & $11: 30 h$ & $12: 00 h$ & $12: 30 h$ & $13: 00 h$ & $13: 30 h$ \\
\hline Room A & 72.5 & 68.0 & 69.7 & 69.9 & 69.3 & 72.0 & 73.8 \\
Room B & 72.0 & 73.4 & 74.9 & 73.1 & 76.0 & 74.8 & 72.7 \\
Room C & 75.0 & 67.7 & 70.0 & 71.7 & 73.7 & 75.1 & 74.6 \\
Room D & 80.0 & 76.4 & 77.6 & 78.8 & 80.0 & 80.5 & 79.0 \\
\hline
\end{tabular}


Table 7

Variation of temperature during the second campaign of interruptions in drying rooms

\begin{tabular}{cccccccc}
\hline \multicolumn{6}{c}{ Temperature (ㅇ) } & \multicolumn{7}{c}{} \\
\hline Room & Reference & $11: 00 h$ & $11: 30 h$ & $12: 00 h$ & $12: 30 h$ & $13: 00 h$ & 13.30 \\
\hline Room A & 30.0 & 26.3 & 26.1 & 27.8 & 28.1 & 30.4 & 30.6 \\
Room B & 18.0 & 18.0 & 18.1 & 18.3 & 18.7 & 19.2 & 18.4 \\
Room C & 8.0 & 8.0 & 8.0 & 8.4 & 8.6 & 9.0 & 8.2 \\
Room D & 4.0 & 3.1 & 3.5 & 3.9 & 4.0 & 4.3 & 3.1 \\
\hline
\end{tabular}

